\title{
A Study to Assess the Knowledge on Oral Health and Self Esteem among Young Adults in Selected College, in Kancheepuram District, Tamilnadu, India
}

\author{
Gini T.R ${ }^{1}$, Ashika Parveen ${ }^{1}$, Sharmilavathi.A ${ }^{1}$, Avinash.U ${ }^{1}$, Anto Benson ${ }^{1}$, Shanthi ${ }^{2}$ \\ ${ }^{I}$ M.S, B.I, B.Sc (Nursing) III rd Year Students, ${ }^{5}$ Professor Medical Surgical Nursing Department, Chettinad College \\ of Nursing, Chettinad Academy of Research and Education, Rajiv Gandhi Salai , Kancheepuram District, Tamil \\ Nadu, India
}

\begin{abstract}
"A study to assess the knowledge on oral health and self-esteem among young adults in selected college, Kancheepuram district, Tamil Nadu, India". The objectives are to assess the knowledge on oral health among college students and to assess the self-esteem among college students and to correlate the knowledge on oral health and self-esteem among college students and to associate the knowledge on oral health and self-esteem with selected demographic variables among college students. The convenience sampling was used to select 100 young adults. The data collection tools were validated and reliability was established. The data was collected from the students in selected college. The collected data was Tabulated and Analysed. The results revealed that Majority of young adults were female $53 \%$ and $43 \%$ were males. Majority of young adults were in $78 \%$ got information through mobile phone $9 \%$ were got information through newspaper $8 \%$ of young adults got information through television and $5 \%$ of young adults get information through health professionals.

Present study result shows that Mean score of knowledge was 24.58 and mean score of self-esteem was 28.18. There was statistically mild positive correlation was found between the level of knowledge and the level of self-esteem. There is no statistically significant association between selected demographic variables and the level of found knowledge. There is an statistically significant association found between frequency of brushing and frequent rinsing of mouth and level of self-esteem and there is no statistically significant association found between demographic variables.
\end{abstract}

Key Words: Oral health,Self Esteem, Young Adult,Knowledge.

\section{Introduction}

The holistic view of health, which is widely accepted today, sees human life as a total system. The world health is etymologically related to the word - wholeness. Holistic health implies that all aspects of the total system of an individual are in balance with each other. Children are the priceless resource and a nation which neglects them does so at its peril ${ }^{1}$.

Adolescence is the critical time period when skills and attitudes of individuals are taking shape. Due to fast physiological changes going down in a young person, a consciousness and magnified interest concerning one's own body develops. The body image will bring a way of fun, pride, timidness or maybe unhappiness. Knowledge about the prevalence and frequency of different types of dental problems and the need for treatment is important. (2)

It is an amount hard-to-please importantadjustment to the physical and social changes that distinguish childhood behaviour from adult behaviour. The stage of puberty brings in anumberofphysicalandphysiologicalchanges. Theperiodofadolescencenotonly brings physical changes but also psychological changes that make the child a qualitatively different person. These changes affect the personality and adjustment in later life. ${ }^{(3)}$ 
The youth population is burgeoning in some countries, and in these areas and elsewhere adolescents are confronting new situations and threats to their present health, moving towards a future in which their health status is likely to be compromised. The health, education and social sectors are called upon to devise, test and make wider use of effective new approaches, including operational, social science and communitybased research, clinical studies and longitudinal surveys focused on adolescents and youth. Often slow to recognize the essential value of the inter-sectorial approach in meeting the needs of the population, public health institutions in particular need to provide services and train personnel to make sure that no juvenile person slips through the cracks in health care ${ }^{(4)}$.

Apart from the impact on biological process standing, poor dental health can even adversely have an effect on speech and vanity. Dental diseases impose both financial and social burdens as treatment is costly and both children and adults may miss time from school or work because of dentalpain ${ }^{5}$.

The dental problems more common among adolescents are Dental caries, Malocclusion, Periodontal disease, Bimaxillary proclination, Fractured teeth, Missing teeth, Discoloration of teeth. The causes can be poor oral hygiene, infection, lifestyle, accidents ${ }^{(6)}$

The impact of oral diseases, pain, suffering, impaired function and reduced quality of life, is both extensive and expensive. Most of the time managing of such problems is beyond the resources of many developing countries. Dental diseases are widely prevalent, more so in the developing countries like India. Dental health education is an integral part of dental health services and has been provided in various settings like dental office and dental institutions, school and other educational institutions ${ }^{(7) .}$

Dental diseases are widely prevalent, more so in the developing countries like India. Dental health education is an integral part of dental health services and has been provided in various settings like dental office and dental institutions, school and other educational institutions ${ }^{(8) \text {. }}$

No matter the temporal order of the physical changes that come about throughout adolescence, this can be a amount during which physical look unremarkably assumes preponderant importance. Both girls and boys are known to spend hours concerned about their appearance. $^{(9)}$

Issues of oral health revolve almost exclusively around dental caries and it is very important in developing countries like India. Dental caries incidence begins within the permanent teeth at concerning six years with the eruption of central incisors and initial molars. Among kids five to eleven years more matured, twenty sixth have older one or additional lesions in permanent teeth; this proportion will increase to sixty seven among adolescents twelve to seventeen years of age. ${ }^{(10)}$

A longitudinal study was conducted to assess the extent of dental anxiety among young adults. Data were collected from 697 youngsters whose age is from 16 to 19 yrs. The study results showed that women expressed $7.73 \%$ anxiety which was more than in men $6.78 \%$. $^{(11)}$

The psychological problems touching folks that should agitate the loss of a tooth, in addition as make a case for however this loss will have an effect on the standard of life. The most important impact of tooth loss is on he looks and social relations element of quality of life as a result of folks cannot modification their appearance with missing teeth. ${ }^{(12)}$

A study found that once subjects went through associate some 20-minute long interview with associate queried that they believed had an occasional opinion of them, their vanity was markedly lower after the interview. Poor physical appearance leads to a lowered opinion by others, which logically leads to lower popularity and lack of popularity may undermine self-esteem and selfconfidence. $^{13}$

Adolescents (10-19 years) form a large section of population - about $22.5 \%$, that is, about 225 million. They are living in diverse circumstances and have diverse health needs (Census 2001). ${ }^{(14)}$

The largest and the most important group that may be reached by health education is found in the school system. ${ }^{15}$

\section{Materials and Method}

A Quantitative, Evaluative research approach was appropriate for the study.Non interventional descriptive research design was most appropriate for the study. The 
participants of the study will be selected by convenient sampling technique. The sample size 100 who fulfil the sampling criteria.

Age from 18 years to 25 years, Both male and female gender who are willing to participate in the study and who understand Tamil and English were included in the study. Those who are not willing to participate in the study and not available at the time of data collection were excluded from the study. Standardized administered questionnaire was used to elicit demographic variables and self-esteem scale was used to assess level of knowledge on oral health and self-esteem among young adults and score was interpreted as follows 88-120 high self-esteem ; 57-88 moderate self-esteem ; 24-56 low self esteem .

\section{Finding and Discussion}

\section{Knowledge:}

The majority of young adults $(65 \%)$ were in age group of 18 to 20 years , $46 \%$ were $3^{\text {rd }}$ year , $(63 \%)$ were religion Hindu , $85 \%$ were in source of drinking water purified water, $87 \%$ were belongs to non-veg, $78 \%$ were in get information through mobile phone.

There is no statistically significant association between selected demographic variables and the level of found knowledge.

\section{Selfesteem}

$76 \%$ of young adults had average level of knowledge where as $24 \%$ of them had good knowledge on oral health among young adults $26 \%, 54 \%$ and $20 \%$ had low, moderate and high level of self-esteem respectively.

There is an statistically significant association found between frequency of brushing and frequent rinsing of mouth and level of self-esteem and there is no statistically significant association found between demographic variables.

Table 1 : Distribution and Association of Knowledge on oral health and self Esteem with selected demographic variables among college students.

\begin{tabular}{|l|l|l|l|l|}
\hline S.N & Variables & $\begin{array}{l}\text { Frequency \& } \\
\text { Percentage }\end{array}$ & $\begin{array}{l}\text { Knowledge } \\
\chi^{2}\end{array}$ & $\begin{array}{l}\text { Self Esteem } \\
\chi^{2}\end{array}$ \\
\hline & & & & \\
\hline
\end{tabular}

Table 2 :- Correlation between Knowledge on Oral Health with Self Esteem

\begin{tabular}{|l|l|l|l|}
\hline Aspects & Mean & SD & $\gamma$ value \\
\hline Knowledge & 24.58 & 5.115 & \multirow{2}{*}{$0.5115^{*}$} \\
\hline Self Esteem & 28.18 & 10.722 & \\
\hline
\end{tabular}

Mean score of knowledge was 24.58 and mean score of self-esteem was 28.18 . There was statistically mild positive correlation was found between the level of knowledge and the self esteem among young adults.

\section{Conclusion}

Present study was conducted to assess the knowledge on oral health andself -esteem among young adults. The results found that there was statistically mildpositive correlation was found between the level of knowledge and the level of self- esteem and also reveals that there is an statistically significant association found between frequency of brushing and frequency rinsing of mouth and level of self -esteem therefore investigator concluded that oral hygiene practices among young 
adults are not following the oral hygiene because of lack of time to go for dental check-up.

\section{Self-Esteem.}

Ethical Clearance: Ethical clearance was obtained from institutional human ethical committee chettinad academy and education. Formal written permission obtained from hospital authorities. Consent was obtained from each participants after explaining the procedure.

\section{Conflict of Interest -Nil}

Source of Funding - Self

\section{Reference}

1). Singh MK, Abdulrahman militia, Rashid A Indian Journal of Dental analysis. 2018 may 1;29(3):378. Gambhir RS, Gupta T. would like for oral health policy in Bharat. Annals of medical and health sciences analysis. 2016; 6(1):50-5.

2). Kamble VS, Biradar SM, Takpere A, Reddy S. information of hand hygiene practices among students of ESIC medical school, Gulbarga, Karnataka, India. International Journal Of Community medication And Public Health. 2017 Jan 31; 3(1):94-8.

3). Shekar BC, Reddy CV, Manjunath BC, Suma S. Dental health awareness, attitude, oral healthrelated habits, and behaviours in reference to socioeconomic factors among the municipal workers of Mysore town. Annals of medicine and Public Health. 2011 Jul 1;4(2):99.

4). Singh A, Gambhir RS, Singh S, Kapoor V, Singh J. Oral health: what quantity does one know?-A study on knowledge, perspective and practices of patients visiting a North Indian school. European journal of dental medicine. 2014 Jan;8(1):63.

5). Paul B, Basu M, Dutta S, Chattopadhyay S, Sinha D, Misra RJournal of medical practice and first care. 2014 Apr;3(2):107.

6). Naseem S, Fatima SH, Ghazanfar H, Haq S, Khan NA, Mehmood M, Ghazanfar A. Oral hygiene practices and teeth cleansing techniques among medical students. Cureus. 2017 Jul;9(7).

7). Desai K, Patel S. Assessment of Oral Hygiene Awareness among school Students in Surat town. National Journal of Community drugs. 2018;9(3):236-9.
8). Kapoor D, Gill S, Singh A, Kaur I, Kapoor P. Oral hygiene awareness and follow amongst patients visiting the department of periodontology at a dental school and hospital in North India. Indian journal of medical specialty. 2014 Apr;5(2):64.

9). Daya D, Teja U, Paturu DB, Reddy BV, Nagarakanti S, Chava VK. analysis of oral-hygiene awareness and apply among dental students. Journal of Dr. NTR University of Health Sciences. 2017 January $1 ; 6(1): 24$.

10). Kumar H, Behura SS, Rama S, Nishat R, Dash KC, Mohiddin G. Oral health information, attitude, and practices among dental and medical students in jap India-A comparative study. Journal of International Society of Preventive \& Community odontology. 2017 Jan;7(1):58.

11). Hegde A, Venkataramana G, Kulkarni SB, Bhaskar NN, Jacob J, Gangadharappa SK. Attitudes, experiences, and barriers to analysis and commercial enterprise among dental postgraduate students of Bengaluru City: A cross-sectional study. Journal of Indian Association of Public Health odontology. 2017 Gregorian calendar month 1;15(2):157.

12). Shekar S, Chandrashekar BR, Bhagyalakshmi A, Avinash BS, Girish MS. Knowledge, attitude, and practices associated with treatment among faculty students in rural and concrete areas of Mysore, India: A cross-sectional form study. Indian Journal of Oral Health and analysis. 2017 Jan 1;3(1):9.

13). Gualie YT, Tayachew AT. Assessment of information, attitude, and follow toward oral hygiene among governmental school students in Debretympan city, Amhara Region, North Central Federal Democratic Republic of Ethiopia 2018: Institutional-based cross-sectional survey. International Journal of Oral Health Sciences. 2018 Jul 1;8(2):92.

14). Gaffney A, Himmelstein DU, Woolhandler S, Angell M. on the far side the cheap Care Act: A Physicians' Proposal for Single-Payer Health Care Reform.

15). Balasuppramaniem M, Sundaram E, Gainneos RD, Karunamoorthy V, Panneerselvan VE, ThiruppathiP.analysis of oral hygiene self-efficacy, knowledge, and motivation among young adults of rural-based tamilian population: A prospective cohort study. Journal of Indian Society of Periodontology. 2017 Jan;21(1):55s. 